\title{
$\$$ Research Square \\ Health City and Fair Treatment: Medical Treatment Behaviour of the Elderly Population in Shanghai
}

\section{Shangguang YANG}

East China University of Science and Technology

Danyang WANG ( $\nabla$ dywang007@163.com )

East China University of Science and Technology https://orcid.org/0000-0003-0897-1314

Chen Li

Institute of Future Cities,Department of Geography and Resource Management,the Chinese University

Chunlan Wang

East China Normal University

Mark Wang

The Unversity of Melbournr

\section{Research article}

Keywords: Elderly population, Medical treatment behaviour, Influencing factors, Shanghai, China

Posted Date: July 1st, 2020

DOI: https://doi.org/10.21203/rs.3.rs-39221/v1

License: (c) (i) This work is licensed under a Creative Commons Attribution 4.0 International License.

Read Full License 


\title{
Health City and Fair Treatment: Medical Treatment Behaviour of the Elderly Population in Shanghai
}

\author{
ShangguangYang1, Danyang Wang1*, Chen $\mathrm{Li}^{2}, \mathrm{ChunlanWang}^{3}$ and Mark Wang ${ }^{4}$ \\ Adress: ${ }^{1}$ School of Business, East China University of Science and Technology,130 Meilong Road, \\ Shanghai, CHN, ${ }^{2}$ Institute of Future Cities, Department of Geography and Resource Management, \\ the Chinese University of Hong Kong, CHN, ${ }^{3}$ Chinese Modern City Research Center, School of \\ Social Development, East China Normal University, CHN and ${ }^{4}$ School of Geography, the \\ University of Melbourne, AUS
}

Email: sgyang@ecust.edu.cn; dywang007@163.com*; chen.li@cuhk.edu.hk; clwang@soci.ecnu.edu.cn;

myw@unimelb.edu.au

* Corresponding author

\begin{abstract}
Background: Issues related to the satisfaction of the elderly population towards health and medical services have become an increasing social concern in China, under the influence of individuals, medical institutions and social factors, the structural contradictions of the elderly population's demand in terms of medical and health services are very prominent. This study seeks to assist in the resolution of issues faced by the elderly when dealing with their medical needs and improve the quality of medical services in megacities in China.
\end{abstract}

Methods: This study analyses the difference in behaviour of the elderly towards medical treatment in Shanghai based on 625 questionnaires. The investigation mainly includes five parts: personal information, health status, elderly person's medical preference and expectation, satisfaction towards hospitals and medical services, and medical insurance mode and the level of success from use. The study uses Multinomial logistic regression to investigate the influencing factors.

Results: To the elderly group in Shanghai, their medical treatment behaviors based on rational choices around price, demand and supply of medical services. The stratification of medical services based on the economic and social characteristics of the elderly population is obvious. Overall, our results show that, firstly, factors such as age, marriage status, relationship, residential location and medical treatment distance have great impacts on the elderly population's medical treatment choices. Secondly, Chinese elderly people rely heavily on family support. Thirdly, medical treatment behaviour has a distance friction effect: the closer to hospital, the stronger the tendency to choose. Fourthly, Shanghai and other big Chinese cities are in the stage of population suburbanization, but the allocation of public service resources, such as medical, health and education, still presents a strong centripetal agglomeration in space.

Conclusions: The study further contributes to public resource distribution and justice between different groups of people in the context of social stratification. while strengthening the reform of medical marketization and improving the efficiency of supply of scarce medical products, the Chinese government should also strengthen the reform of system design and strengthen the total supply and structural balance of geriatric care, especially the weak geriatric products.

Keywords: Elderly population; Medical treatment behaviour; Influencing factors; Shanghai; China 


\section{Background}

Issues related to an aging population have become an increasing concern worldwide. One of the most significant issues is the health problems of the elderly. However, under the influence of individuals, medical institutions and social factors, the structural contradictions of the elderly population's demand in terms of medical and health services are very prominent. Therefore, identifying the health and medical needs of the elderly and providing relevant medical and health services that match with such needs are crucial both academically and practically.

The rapid growth of the elderly population will have significant impaction megacities in China in the coming decades. Shanghai is the first city entering into the aging society of China. The rate of aging in Shanghai is the highest among the Chinese megacities and at a high level compared with other megacities in the world. In 2017, the proportion of permanent residents over 65 years old reached $14.3 \%$ of Shanghai's total permanent residents [1]. Although Shanghai has built a medical and health service system covering both urban and rural areas composed of hospital, basic-level medical and health care institutions and professional public health institutions, due to inefficient allocation of health resources and medical market failure, normal medical needs cannot be effectively met.

It is the scarcity of total medical resources and disequilibrium of health care facilities, that makes the balance and equalization of medical resources is becoming one of the most important indicators of urban social equity and justice. With the increase in the proportion of the elderly population in many large cities in China, there are obvious differences in the medical and health resources enjoyed by the elderly population in different urban areas and different social strata groups. It is becoming an important manifestation of social inequity in contemporary Chinese large cities, and has become the great challenge facing urban governance. The Central Committee of the Communist Party of China on Several Major Issues in Comprehensively Deepening Reform Make it clear we need to stick A New Road to Urbanization with Chinese Characteristics This is the way to promote urbanization characterized by "intensive, harmonious, fair, and sustainable" and centered on people. In the future, China's new urban governance transformation should pay more attention 
to people's needs, and pay more attention to issues such as the accessibility, convenience, and enjoyment of spatial equality of public resources such as medical, health, and education of different social class groups.

This presents the importance and complexity of medical needs and services in Shanghai. In recent years, the planning and reform initiatives for the medical and health service system has moved towards a 'people-oriented' perspective in China. However, in Shanghai, the elderly population is encountering different medical conditions depending on which social group they are from. This drives the need to analyse the challenges faced by medical reform measures such as hierarchical medical treatment from heterogeneous characteristics of residents' micro-behaviors.

This study investigates the influencing factors of the elderly population's medical treatment choices in Shanghai. Such investigation is based on the Multinomial logistic regression and covers three medical conditions: physical discomfort, general disease and severe disease. This study contributes to solve the problems of elderly population's medical needs and improve the quality of medical services in megacities in China. This study seeks to assist in the resolution of issues faced by the elderly when dealing with their medical needs and improve the quality of medical services in megacities in China.

\section{Literature review and Theoretical Basis}

Western scholars study the medical service market from the perspective of welfare economics and health economics is incorporated into the analysis framework of mainstream economics [2]. Academic adopt micro-equilibrium analysis to construct human capital investment equilibrium model and propose the methods of analysing the basic concept framework and system of human capital [3]. Then further applied to health and medical services research and for the first time establishes the theoretical model of health and medical service demand based on family production function [4]. This model theory has become the benchmark for the following research on medical needs, and some representative empirical studies have been emerging with the development of the model theory. For example, to analyse medical needs, the two-part model has become the classic 
method of analysis and modelling in health economics [5]. The economic analysis of medical service market resource allocation and welfare has then gradually formed strong links with mainstream socioeconomic activities [6].

\section{Healthy City}

In 1994, the WHO defined a healthy city as "a healthy city should be an organic combination of healthy people, a healthy environment and a healthy society. It should continuously improve the environment and expand community resources so that urban residents can support each other. To maximize their potential". From all aspects of urban planning, construction and management, healthy cities should focus on human health, ensure the healthy life and work of the general public, and become an integrated development of the healthy population, healthy environment and healthy society required by the development of human society. Healthy cities involve not only some traditional public health issues, but also social fields (culture, education, welfare, security), ecological environment (ecological balance, pollution control and resource protection), community life (healthy community neighborhoods) Relations, civilized fashion, etc.), personal behavior (mental health, behavior correction, and encouragement of healthy lifestyles, etc.), social justice (elimination of isolation between social classes, priority of public transportation, etc.) and other non-public health fields [7]. The planning and construction of medical and health undertakings are important measures to promote the realization of the concept of a healthy city.

In China, the level and quality of medical care determine the grade of public hospitals. Chinese hospitals have a strict grading system which are mainly divided into third-level general hospitals, second-level general hospitals and first-level general hospitals. The tertiary hospital is the highestranking hospital in China, with high-quality medical services and management, medical quality, and high technical level and efficiency. The primary hospitals that directly provide comprehensive medical, prevention, rehabilitation, and health care services to the community are classified as firstlevel hospitals. In addition, there are also unrated hospitals, such as community service centers. The 
treatment gap between different levels of medical resources is large, and the level of medical services is closely related to residents' medical behaviors and medical process.

The uneven distribution of medical resources is closely related to the administrative level and power of cities. An evaluation framework to assess hospital quality in china and found that the health care gap is due to the uneven distribution of high-quality hospitals. China's administrative system allocates people, money and goods to public hospitals of different stripes and grades [8]. Once the block and grade structure established, it is necessary to establish the corresponding stratification mechanism to maintain the structure. According to the allocation of people, money and things, education and employment mechanism, fund-raising payment mechanism and planning control mechanism are carried out to realize the allocation of resources, which leads to the systematic stratification and difference of medical quality. The administrative subordinating relation means the difference in government financial resources. The administrative level and the level of regional economic development determine the local government's investment in medical institutions. Secondly, the social selection mechanism of people's medical treatment process has further exacerbated this systematic difference, resulting in a huge gap in the level of human resources between regions, urban and rural areas and medical and health institutions at different levels. Finally, although the government has prepared various plans to allocate medical and health resources, such as implementing institutions, personnel, and financing and payment reforms, there are always insufficient constraints, resulting in a slightly weaker quality improvement. Even worse, under the market system, public hospitals have the ability to obtain resources through the market. It is difficult for the government to fully control the facilities and equipment configuration of public hospitals with the policy standards established by the plan. Public hospitals also have very strong political influence. They can lobby party and government leaders to break through the restrictions imposed by regional health planning on their facilities and equipment.

Medical justice 
Medical justice is the basis of social justice, the basic basis for the design of health care systems, and the minimum standard and necessary conditions for medical order. Reasonable arrangement of medical justice system is conducive to eliminating the gap between social groups, reducing medical disputes and enhancing social harmony.

The importance of health care is that it protects people's "normal species function", thereby providing everyone with a fair share within the "normal opportunity range" necessary prerequisites [9]. System justice in the field of medical services is the value dimension followed by the reform of the medical system [10]. However, government regulatory preferences and the effectiveness of government power operations will affect the essence and operation of medical justice. Compared the justice ethics of contemporary medicine from the perspective of Chinese and Western justice, medical justice is the most basic and minimum morality in a society, and it is also the most important morality [11]. China's medical order management must pay attention to the legal relationship between order and justice, pay attention to the justice demands of the doctor-patient group, and seek order harmony from the overall justice of the system. On the one hand, it promotes the fair allocation of medical resources between different regions and groups, on the other hand, it focuses on the highly professional and high-risk characteristics of medical behaviors, and promotes the fair allocation of doctor-patient rights in the medical relationship [12]. But China's existing medical security system fails to give rare patients as a socially disadvantaged group due to more complete medical security, unfair distribution of medical resources and other medical security rights and interests are difficult to maintain [13].

In the 21st century, health problems based on income have been deepened. More and more scholars have begun to pay attention to the relationship between income gap and health level and the positive and negative effects of income gap on health level. Most scholars believe that the income gap has a significant negative impact on health. The China Health and Nutrition Survey (CHNS) data used to study the concentration coefficient method and found that income factors have a negative impact on the health level [14]. Used The income gap of the lag period to conduct 
an empirical regression on the health level, and concluded that the impact of the income gap on health is inverted U-shaped [15]. It is also believed that the popularity of public medical policies can improve the adverse health effects of income disparities. On this basis, it is also believed that the popularity of public medical policies can improve the adverse health effects of the income gap. Although income gaps have a significant negative impact on health, social capital can buffer the negative impact of income gap on health [16]. Verified the micro-survey data of Jiangsu and other places under Roemer's equal opportunity theory, Urban-rural medical insurance co-ordination system should pay attention to the substantive equity of urban and rural residents' medical and health [17]. Compared with the non-implemented areas, the urban and rural areas implementing medical insurance co-ordination significantly alleviated the unequal opportunities in the use of medical services and health levels of residents. Compared to unimplemented areas, the areas where urban-rural medical insurance co-ordination is implemented have significantly eased the inequality of opportunities for residents 'use of medical services and health.

\section{Distribution of medical resources}

Public service facilities are space carriers carrying public services, which can be divided into fixed-point facilities services, non-point facilities services and network facilities services based on spatial distribution characteristics. Among them, the designated facilities service needs residents to reach the facilities to get, such as schools, hospitals, parks, libraries, gymnasiums and so on, the spatial distribution of the different social class accessibility differences and unfairness is the most prominent, so it has become the main type of related academic research facilities. Rational allocation of medical resources is a key part of the equalization of medical services, so most countries around the world have been vigorously deepening the reform of the medical and health system, trying to reverse the unreasonable allocation of medical resources and guide the healthy development of the medical market in a just and reasonable direction.

The public service facilities fairness evaluation method mainly uses GIS to measure accessibility. The measurement method has undergone a transition from "land-based" to "person- 
based". Differences in demand and utilization patterns are included in the research analysis [18].

The description and analysis of the spatial allocation of medical resources are mostly realized by means of geographic information technology[19-22]. Such as using arc-gis network analysis expansion method, by determining the shortest path Lorentz curve and Gini coefficient, the accessibility and fairness of medical resources in Tianhe District of Guangzhou are studied. Used geographic statistical methods to and study the rationality of the spatial distribution of medical conditions in various provinces in China, and found that there is an imbalance in the distribution of medical conditions in China. The distribution of medical facilities and resources is mainly guided by population and economic development, and is concentrated in Beijing, Shanghai and other eastern coastal provinces, but for some underdeveloped areas in the west, the current medical conditions cannot meet their needs. Started from the research of Grade A hospitals, and believed that their spatial distribution was very uneven, resulting in the problem of "difficult to see a doctor" in terms of geographical accessibility. The top three hospitals are not only concentrated at the prefecture-level city level, but also have significant spatial differentiation at the regional and even national levels. The referral reform has improved the overall accessibility of Beijing's public hospitals, but at the same time has exacerbated the inequality of access to medical resources in cities and streets.

\section{Access to health care for the elderly}

As the number of elderly people visiting doctors and being hospitalised are counting data with highly discrete characteristics, traditional statistical methods such as OLS are difficult to be applied to analyse elderly population's medical needs. Selecting the appropriate research method is an 
important premise to accurately explore the elderly population's medical behaviours. Current research on elderly population's medical needs is mainly based on the Negative Binominal Model (NBM), Tobit model and Logistic model. A Finite Mixed Negative Binominal (FMNB) model was built to discuss the influences of self-health assessment, numbers having chronic diseases, demographic characteristics (race, gender, marriage status and education), economic factors (family income and occupation), public medical insurance and commercial medical insurance on elderly people's medical service demands [23], this research is based on the sample of 4,406 elderly people aged over 66 years in the National Medical Expenditure Survey in the US in 1987. Scholar use the negative binominal regression model to analyse the numbers of local elderly people and immigrant elders visiting doctors in 11 European countries and find a positive correlation between the medical service use and health investment of immigrant elders and the distribution density of doctors [24].

With China's deepening aging population, the elderly population has become the group that has the largest demand for medical services. Their health needs and medical care have become the focus of the society[25]. Parents' medical treatment behaviours are affected by social, demographic and economic factors, medical needs and medical insurance, including the selections of medical institutions, medical staff, timing of treatment, medicine and treatment methods[26]. Factors influencing residents' medical treatment behaviours include age, education level, income level, frequently visiting medical institutions, disease severity, medical and health service accessibility and medical care assurance pattern [27]. Elderly population's medical behaviours are mainly influenced by economic income, medical insurance and health service resource allocation [28]. Delayed diagnosis and treatment is an important factor affecting patients' medical treatment behaviours [29]. Community residents' medical treatment are affected by the diagnosis and treatment level of medical institutions and their physical conditions. Low-income families tend to go to small hospitals or clinics, while high-income families tend to go to level-3 hospitals [30]. When seeking medical treatment, community residents are affected by the diagnosis and treatment level 
of medical institutions, and as a group with high medical risks, retired people need to establish supplementary medical insurance measures to solve their demand issues [31].

Chinese scholars mainly adopt two methods when studying medical treatment behaviour: one is to use traditional panel regression analysis, and another is to use the Multiple Logit Model (MLM) and Conditional Logit Model (CLM). Such as according to CLHLS survey data in 2008, construct Stepwise and Logistics models to empirically study the influences of medical security on elderly people's medical service demand and find that medical security reduces family burden and in turn increases elderly people's medical service demand and improves the medical treatment rate [32]. Adopting the Logistic model to analyse medical service utilisation of the elderly population aged over 60 years old in Heilongjiang province, find that the elderly population's medical service demand depends on their types of medical insurance, chronic disease status, body function, selfhealth assessment and body check within one year [33]. By using China Health and Nutrition Survey(CHNS) data and constructing a Logit model to study the influence of medical insurance on resident's medical treatment behaviours, find that medical insurance plays a guiding role to medical treatment selections [34].

However, there are three significant gaps in the previous. First, the previous studies use a nationwide large-scale survey database, which are more applicable to nationwide studies but fail to represent the issues in specific megacities in China. Second, micro empirical studies on residents' medical treatment behaviour in Chinese megacities are lacking. Third, studies and attention on the elderly population's medical treatment behaviour is rare. The existing studies on factors that influence medical treatment behaviour lack a categorisation by ages.

\section{Methods}

\section{Data source}

The data for this study is from questionnaires conducted from November to December 2017 in Shanghai. Shanghai is selected because it is the most developed city in China and is facing significant class differentiation in its population. The investigation mainly includes five parts: 
personal information, health status, elderly person's medical preference and expectation, satisfaction towards hospitals and medical services, and medical insurance mode and the level of success from use. We investigate the following:

- personal information in order to understand basic demographic characteristics (gender, age, marriage status, and relationship);

- hukou place and residential place;

- socioeconomic status (education level, employment and income);

- health status in order to understand the reason for the medical service (self-evaluation of physical health and whether it involves chronic disease);

- medical preference and expectation in order to understand medical habits and behavioural choices;

- satisfaction of hospitals and medical services in order to understand current situation of hospital and medical service supply; and

- medical insurance mode and the level of success in using it in order to understand medical security status (whether basic medical insurance is held).

The preliminary investigation was conducted in Minhang district, Xuhui district and Fengxian district by randomly selecting 20 elderly people aged over 60 years old. We chose people aged over 60 years old because according to the United Nation's definition, when the proportion of people aged over 60 years old exceeds $10 \%$ of that country or region's total population, the country or region is classified as an aging society.

The formal investigation was based on the modified preliminary investigation and conducted in 12 districts in Shanghai. These districts include Jing'an, Huangpu and Hongkou in urban core areas, Xuhui, Changning, Putuo and Yangpu in urban fringes, Pudong, Minhang, Baoshan and Jiangding in suburbs and Jinshan, Songjiang, Fengxian, Qingpu and Chongming in outer suburban areas. The investigation covered 39 streets, 132 neighbourhood committees and 6 rural committees. The investigation respondents were from all the areas divided by Shanghai's inner ring, middle 
ring and outer ring: 39 lived within inner ring, 30 lived between inner ring and middle ring, 35 lived between middle ring and outer ring and 34 lived outside outer ring.We issued 638 questionnaires, got 638 questionnaires back with 625 'valid' questionnaires (554 were urban samples and 71 were rural samples).

The average distance from the investigation respondents' residential place to the closest hospitals (level-2 and level-3) is 2089.7 metres, to the closest level-2 hospitals is 2217.4 metres and to the closest level-3 hospitals is 1707.3 metres. The hospitals mentioned here do not include specialist hospitals, such as ophthalmological department, dental department and chest department. The ages of the respondents are mainly concentrated in the group of 'younger' elderly people, which is in line with the proportion results in the 2010 Population Census. In the investigation, about $80 \%$ are married and have a spouse, about $15 \%$ are widowed and the numbers of divorced and unmarried are small. Nearly half of the respondents live with their spouse while about $40 \%$ live with their children and grandchildren. More than half of the respondents have education levels of middle school or below and only $13 \%$ have specific college education or above. In the investigation, about 95\% respondents have Shanghai hukou and about $88 \%$ had formal employment before retirement. Also, among the elderly respondents, the monthly retirement pension is between 3,000 to 5,999 Yuan.

\section{Variables set}

This study investigates medical needs and behaviour for three conditions: physical discomfort, general disease and severe disease. When there is physical discomfort, elderly people have four choices: go to hospital, go to the pharmacy, 'endurance'(stay at home) and taking other measures. Going to hospital is set as a control group in this study because it is a direct medical treatment behaviour indicating that elderly people have higher health awareness and more sensitive and prudent self-medical judgement. When there are common diseases, severe diseases and follow-up treatment after severe diseases, the elderly population's treatment options include going to general hospital (level-3), district or regional hospital (level-2) and community health service centres and 
other medical institutions. In China, general hospital (level-3) is a hospital that provides medical and health services across regions, provinces, cities and nations, and a centre for medical prevention technology with comprehensive medical, teaching and scientific research capabilities. Theoretically, elderly people will have the highest quality of medical supply when they choose general hospital for disease and follow-up treatment. Therefore, this study sets going to general hospital as the control group.

Explanatory variables are composed of four groups: socio-economic characteristics, medical needs, medical resources availability and medical expenditure. Socio-economic characteristic variables include gender, age, income (referring to retirement pension), marriage status, cohabitation status, educational level, residential location (urban and rural) and residential status (hukou/ household registration). Males, aged between 60 to 64 years old, income less than 1,000 Yuan, married with a spouse, cohabitation of husband and wife, educational level of primary school or below, rural hukou and non-Shanghai hukou are set as the control group. Medical needs variables include self-evaluation of physical health and whether it is a chronic disease, and very healthy and no chronic disease are set as the control group. The availability of medical resources is highly related to the elderly person's self-perception of their health. Therefore, the variables are divided into subjective and objective for comparison, including the closest hospital level (level 2 or level 3) and distance. The closest hospital (level 2) and within $1 \mathrm{~km}$ are set as the control group. Medical expenditure variables include the degree of understanding of medical insurance reimbursement policy, preference for hospitals with higher reimbursement rates, and no understanding of medical insurance reimbursement policy and preferring hospitals with higher reimbursement rate are set as the control group.

In addition, the questionnaires also involve commercial insurance and medical insurance copayment methods. The questionnaires show that elderly people rarely purchase commercial insurance and pay by themselves for medical insurance co-payment. 
In order to find the factors influencing the elderly population's different medical needs and behaviour in Shanghai, this study constructs the utility function representing individual medical health demand behaviour based on the medical health models established by many scholars[35-38]. Their modelling paradigm is from micro individual utility theory perspective and obtains empirical evidences by building individual medical health demand model and using parameter estimation. The significance of their models lies in explaining individual medical treatment choices from the utility theory perspective, uses quantitative methods to incorporate patients' medical treatment choices into the unified model, and from micro-perspective to discusses different factors that influence patients' medical treatment behaviours and the quantitative relationship between these factors and individual medical treatment behaviours.

The utility model in this study is as follows:

$$
U_{i j}=U_{i j}\left(X_{i}, N_{i}, D_{i}, E_{i}\right)(i=1,2, \cdots, n ; j=1,2, \cdots, J)
$$

In (1), $U_{i j}$ represents the random utility brought about by medical treatment behaviour $j$, which is taken by elderly individual $i ; X_{i}, N_{i}, D_{i}$ and $E_{i}$ are four types of factors, respectively representing elderly population's socio-economic characteristics (gender, age, income and marriage status), medical needs (the health status of the elderly), medical resources availability (levels of the surrounding hospitals and the distance) and medical expenditure (medical reimbursement). The elderly population's medical treatment choices include going to hospital, going to pharmacy, endurance and other measures. Assuming elderly individual's selectable plan is $y=1,2, \ldots, J$, and $J$ is positive integer, then totally there are $J$ mutually exclusive choices. Therefore, the utility function of elderly individual $i$ 's selectable plan is:

$$
U_{i j}=x_{i}^{\prime} \beta_{j}+\varepsilon_{i j}(i=1, \cdots, n ; j=1, \cdots, J)
$$

In (2), $x_{i}^{\prime}$ is elderly individual $i$ 's characteristic vectors, including $X_{i}, N_{i}, D_{i}, E_{i}$, they change with the individuals. $\varepsilon_{i j}$ is random error term; $\beta_{j}$ is estimated parameter. 
If the ith elderly individual who has $j$ options and chooses $j$, this means that for this individual, $\mathrm{j}$ has the utility maximisation among the $\mathrm{j}$ options, that is $U_{i j}$ is the largest. Then, the probability of statistical model choosing $j$ is:

$$
\begin{aligned}
P_{i j} & =P\left(U_{i j}>U_{i k}, \forall k \neq j\right) \\
& =P\left(U_{i k}-U_{i j} \leq 0, \forall k \neq j\right) \\
& =P\left(\varepsilon_{i k}-\varepsilon_{i j} \leq \beta_{k} \bullet x_{i}^{\prime}-\beta_{j} \bullet x_{i}^{\prime}, \forall k \neq j\right)
\end{aligned}
$$

Multinomial logistic regression is a prediction model, which is used to predict the probability of different possible outcomes of likelihood distribution dependent variables [39]. Assuming $\varepsilon_{i j}$ conforms to the condition of IIA and obeys the extreme value distribution of type I, giving a set of independent variables (four variables in this study), assuming $y$ is independent and identically distributed variable and has 4 categories, then polynomial regression is composed of 4 Logistic models, if $\beta_{1}=0$, then,

$$
P=\left(y_{i}=j \mid x_{i j}\right)=\frac{\exp \left(x_{i j}^{\prime} \beta+z_{i}^{\prime} \beta_{j}\right)}{\sum_{k=1}^{J} \exp \left(x_{i k}^{\prime} \beta+z_{i}^{\prime} \beta_{k}\right)}
$$

Setting going to hospital as control group when elders are physical discomfort, we assign the value as 0 to calculate the probabilities of $y_{1}$ picking each of the 4 categories.

$$
P\left(y_{1}=1 \mid x^{\prime}\right)=\frac{1}{1+\sum_{k=2}^{4} e^{x^{\prime} \beta_{k}}}, P\left(y_{1}=2 \mid x^{\prime}\right)=\frac{e^{x^{\prime} \beta_{2}}}{1+\sum_{k=2}^{4} e^{x^{\prime} \beta_{k}}}, \cdots, P\left(y_{1}=4 \mid x^{\prime}\right)=\frac{e^{x^{\prime} \beta_{4}}}{1+\sum_{k=2}^{4} e^{x^{\prime} \beta_{k}}}
$$

The $k-1=3$ odds of each category $y_{1}$, relatively to the reference category, are given by,

$$
\frac{P\left(y_{1}=2 \mid x^{\prime}\right)}{P\left(y_{1}=1 \mid x^{\prime}\right)}=e^{x^{\prime} \beta_{2}}, \frac{P\left(y_{1}=3 \mid x^{\prime}\right)}{P\left(y_{1}=1 \mid x^{\prime}\right)}=e^{x^{\prime} \beta_{3}}, \frac{P\left(y_{1}=4 \mid x^{\prime}\right)}{P\left(y_{1}=1 \mid x^{\prime}\right)}=e^{x^{\prime} \beta_{4}}
$$

and logarithmising the two members of the equality we obtain 3 log odds, relatively to the reference category, of y that constitute multinomial logistical model.

$$
\ln \frac{P\left(y_{1}=2 \mid x^{\prime}\right)}{P\left(y_{1}=1 \mid x^{\prime}\right)}=x^{\prime} \beta_{2}, \ln \frac{P\left(y_{1}=3 \mid x^{\prime}\right)}{P\left(y_{1}=1 \mid x^{\prime}\right)}=x^{\prime} \beta_{3}, \ln \frac{P\left(y_{1}=4 \mid x^{\prime}\right)}{P\left(y_{1}=1 \mid x^{\prime}\right)}=x^{\prime} \beta_{4} \text { (7) }
$$


Thus, the logit for each non-reference category against the reference category (that it is the 'standard' category to which the others will be naturally compared) depends on the values of the explanatory variables. The model is iteratively adjusted with the maximum likelihood method.

When having general and severe diseases, setting going to level-3 hospital as control group, we assign the value as $0 . y_{2}$ and $y_{3}$ respectively have three categories to choose, so we construct the Multinomial logistic regression as above, and use Maximum Likelihood Estimation (MLE) to calculate $\beta$.

\section{Results}

\section{Description of the sample}

Table 1 below shows the characteristics of the sample. This is the descriptive statistics we use for the models' empirical variables.

Table 1. The characteristics of the sample

\begin{tabular}{|c|c|c|c|c|c|}
\hline Variable & Obs & Mean & Std. Dev. & Min & Max \\
\hline Physical discomfort & 439 & 1.49 & 0.76 & 1 & 4 \\
\hline General disease & 439 & 2.59 & 1.23 & 1 & 5 \\
\hline Severe disease & 439 & 1.46 & 0.82 & 1 & 5 \\
\hline Female & 439 & 0.62 & 0.48 & 0 & 1 \\
\hline Age & 439 & 68.95 & 6.8 & 60 & 91 \\
\hline Wage & 439 & 3382.32 & 1641.15 & 0 & 15000 \\
\hline Unmarried & 439 & 0.02 & 0.13 & 0 & 1 \\
\hline Divorced & 439 & 0.02 & 0.15 & 0 & 1 \\
\hline Widowed & 439 & 0.14 & 0.35 & 0 & 1 \\
\hline house1Living alone & 439 & 0.09 & 0.29 & 0 & 1 \\
\hline With elders (the same generation) & 439 & 0.03 & 0.18 & 0 & 1 \\
\hline With children & 439 & 0.27 & 0.44 & 0 & 1 \\
\hline With children and grandchildren & 439 & 0.12 & 0.32 & 0 & 1 \\
\hline Middle school & 439 & 0.41 & 0.49 & 0 & 1 \\
\hline High school or technical secondary school & 439 & 0.26 & 0.44 & 0 & 1 \\
\hline Junior college and above & 439 & 0.13 & 0.33 & 0 & 1 \\
\hline Urban & 439 & 0.87 & 0.33 & 0 & 1 \\
\hline Shanghai & 439 & 0.97 & 0.18 & 0 & 1 \\
\hline Self-assessment of healthy status & 439 & 2.6 & 0.86 & 1 & 5 \\
\hline Whether having chronic disease & 439 & 0.69 & 0.46 & 0 & 1 \\
\hline The level of the nearest hospitals from home (Subjective distance) & 439 & 0.57 & 0.5 & 0 & 1 \\
\hline The nearest level-3 hospitals from home (Subjective distance) & 432 & 5.07 & 6.06 & 0 & 30 \\
\hline The level of nearest hospitals from home (Objective distance) & 439 & 0.28 & 0.45 & 0 & 1 \\
\hline The nearest level-3 hospitals from home (Objective distance) & 439 & 1.97 & 2.37 & 0 & 11 \\
\hline
\end{tabular}


\begin{tabular}{l|lllll} 
Whether understand medical insurance reimbursement policy & 439 & 3.07 & 0.98 & 1 & 5
\end{tabular}

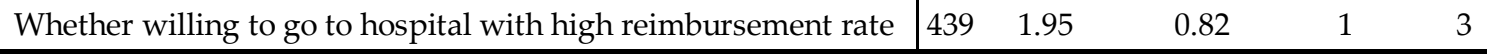

\section{The influencing factors of medical treatment choices for physical discomfort}

Whether elderly people go to hospitals are influenced by various factors when it comes to physical discomfort. As Model 1 shows, age, income, marriage status, cohabitation status, whether having chronic disease, location of household registration and distance to hospitals significantly influence elderly population's medical treatment choices.

First, in terms of socioeconomic characteristics, compared to the youngest elderly population, middle and older elderly population is more willing to choose to go to hospital, especially those aged above 80 years old. There are two reasons. The first reason is that middle and older elderly population have greater decline in their physical functions and higher risks of sudden transformation from physical discomfort to severe disease. Patients and themselves and their families have greater awareness to prevent such transformation. The second reason is that hospitals are able to provide comprehensive examination and experts are able to provide patients with more appropriate treatment methods. Here, we have not distinguished the level of hospital yet for this analysis. The elderly population's selection characteristics on the level of hospital will be further explained.

Apart from the highest income group, compared to the lowest income group, other groups with relatively higher income are more willing to choose to go to the pharmacy rather than hospital. Among these groups, those with monthly income of 1,000 to 1,900 Yuan have higher possibility to go to pharmacy rather than hospital, and this possibility decreases with increasing income. The trend has a fundamental shift for the highest income group: they have higher possibility to go to hospital. When comparing whether elderly people are more likely to go to hospital or endure, the middle income group has higher possibility to go to hospital, while the group with the highest income is more likely to endure than those with the lowest income, due to their superior living environment and healthy knowledge. In the condition of physical discomfort, whether elderly population take active measures or endure may be influenced by many factors other than income, 
as there is no simple corresponding relationship between income and medical treatment behavior. However, the finding shows that high income group is generally more active in seeking treatment when they are in physical discomfort.

Whether elderly people have Shanghai hukou affects their choice in seeking medical help in the condition of physical discomfort. Elderly people with Shanghai hukou have higher possibility of going to hospital than those without Shanghai hukou. Those without Shanghai hukou are still limited by inter-provincial medical insurance reimbursement in hospitals in Shanghai. When they are in the condition of physical discomfort, they are more likely to endure or go to pharmacy. Currently, China is implementing a long-distance medical settlement system. In Shanghai, long-distance medical reimbursement can be done after the transfer of medical treatment relationship and the registration of inter-provincial long-distance medical treatment in medical insurance agencies. Some elderly people do not understand the reimbursement policy before seeking medical treatment and therefore are still affected by the segmentation of medical insurance system.

Second, in terms of medical needs, elderly people with chronic disease have higher possibility to go to hospital. In recent years, in order to improvement chronic disease management, China has implemented a series of policies to control chronic disease prevalence and mortality, such as family doctor services, medical payment ways and people's healthy status improvement. Hospitals are gradually standardising physical examination, carrying out high-risk group screening and intervention, and strengthening early detection and treatment of major chronic diseases.

Third, in terms of medical resource availability, in the condition of physical discomfort, the subjective and objective distances of the elderly people's residential location to the nearest level-2 hospitals significantly influence elderly people' medical treatment behaviours. The subjective and objective distances of the elderly people's residential location to the nearest level-3 hospitals have no significant influences on elderly people's medical treatment behaviours. Compared to the group with the shortest distance, other groups with longer distance are more likely to go to hospital in the condition of physical discomfort, rather than going to pharmacy or enduring. This reflects that 
Shanghai elderly people are active in seeking medical treatment in the condition of physical discomfort: they are more likely to go to hospital to have formal examination and treatment. The quality of medical supply in Shanghai's hospitals has been continuously improved and this has gained the trust of elderly people.

Fourth, in terms of medical insurance reimbursement policy, compared with those who do not understand the policy, those who understand the policy have higher possibility to go to hospital, rather than going to pharmacy, enduring or taking other measures. In the condition of physical discomfort, elderly people who are unsure whether preferring to go to institutions with higher medical insurance reimbursement rate have higher possibility to take other measures.This means that people who are not sensitive to prices accurately exclude hospital visit. This is mainly due to asymmetric information. The elderly population have two kinds of medical preferences. The first one is that they prefer to choose medical treatment according to past experiences. They believe that taking other measures is better for them to resolve their illness issue. They also prefer the same medical treatment choice that they previously made because elderly people receive information slowly compared to younger people. The second one is that elderly people often live alone and lack care from their children. They are afraid that the complicated medical treatment process could bring burden to their children, cannot understand medical insurance reimbursement policy timely and have information bias.

Other factors such as gender, education and residential location (urban and rural) are worth attention.. When in the physical discomfort, females have a higher possibility to go to hospital than males. Education does not influence elderly population's medical treatment behavior. $p$ and elderly population living in urban areas have higher possibility to go to the pharmacy or endure, compared to those living in rural areas. This may be related to the spatial distributions of medical institution and pharmacy in Shanghai: elderly people living in urban areas have a wider variety of choice and better accessibility to pharmacy and hospital, while the distribution of rural pharmacies is relatively 
sparse. Generally, there is one medical institution or village clinic in every village, so elderly people in rural areas are more likely to go to hospital than those people in urban areas.

Table 2. Parameterestimation for the elderly population's measures in the condition of physical discomfort (control group = going to hospital).

\begin{tabular}{|c|c|c|c|c|c|}
\hline \multirow[b]{2}{*}{ sample } & \multirow[b]{2}{*}{ baseline group } & \multirow[b]{2}{*}{ comparable group } & \multicolumn{3}{|c|}{ Parameter estimation (1) } \\
\hline & & & $\begin{array}{l}\text { Going to } \\
\text { pharmacy }\end{array}$ & Enduring & $\begin{array}{c}\text { Other } \\
\text { measures }\end{array}$ \\
\hline \multirow{23}{*}{$\begin{array}{l}\text { Demographic } \\
\text { and economic } \\
\text { characteristics }\end{array}$} & Gender:(Male=0) & Female & -0.28 & -0.43 & -0.10 \\
\hline & \multirow{4}{*}{$\begin{array}{c}\text { Age: } \\
(60-64 \text { years old }=0)\end{array}$} & 65-69 Years old & -0.33 & -0.45 & -1.37 \\
\hline & & 70-74 Years old & $-0.77^{*}$ & -0.49 & -0.31 \\
\hline & & 75-79 Years old & -0.53 & 0.27 & -19.76 \\
\hline & & 80 years old and above & $-1.30^{* *}$ & -1.79 & -1.67 \\
\hline & \multirow{6}{*}{$\begin{array}{l}\text { Income } \\
\text { (retirement pension): } \\
(<1000 \text { Yuan }=0)\end{array}$} & 1000-1999 Yuan & $1.93^{* *}$ & 0.52 & 15.80 \\
\hline & & 2000-2999 Yuan & 0.70 & 0.90 & 17.11 \\
\hline & & 3000-3999 Yuan & 0.07 & 0.59 & 20.42 \\
\hline & & 4000-4999 Yuan & 0.06 & -0.48 & 20.41 \\
\hline & & 5000-5999 Yuan & 0.10 & -0.65 & 22.70 \\
\hline & & 6000 Yuan and above & -0.25 & -0.39 & 21.46 \\
\hline & \multirow{3}{*}{$\begin{array}{l}\text { Marriage status: } \\
\text { (Married with } \\
\text { spouse }=0)\end{array}$} & Unmarried & $2.88^{* *}$ & -25.77 & 2.62 \\
\hline & & Divorce & -1.88 & -17.32 & -20.02 \\
\hline & & Widow & -0.02 & -0.49 & -1.93 \\
\hline & \multirow{4}{*}{$\begin{array}{l}\text { Cohabitation status: } \\
\text { (husband and wife }=0 \text { ) }\end{array}$} & $\begin{array}{l}\text { Elderly people living } \\
\text { alone }\end{array}$ & 0.27 & 1.55 & $4.58^{* *}$ \\
\hline & & $\begin{array}{c}\text { With elder (same } \\
\text { generation) }\end{array}$ & -0.04 & 0.70 & 1.61 \\
\hline & & With children & 0.22 & -0.32 & 1.34 \\
\hline & & With three generations & 0.17 & -0.34 & -15.14 \\
\hline & \multirow{3}{*}{$\begin{array}{l}\text { Education level: } \\
\text { (Primary school } \\
\text { and below=0) }\end{array}$} & Middle school & -0.33 & -0.83 & -1.00 \\
\hline & & $\begin{array}{l}\text { technical secondary } \\
\text { school }\end{array}$ & -0.75 & -0.37 & -0.98 \\
\hline & & Junior college & -0.18 & 0.24 & 0.48 \\
\hline & $\begin{array}{l}\text { Hukou: } \\
(\text { Rural }=0)\end{array}$ & Urban & 0.02 & 0.01 & -3.29 \\
\hline & $\begin{array}{c}\text { Hukou: } \\
\text { (non-Shanghai hukou=0) }\end{array}$ & Shanghai hukou & $-2.24^{* * *}$ & $-2.88^{* * *}$ & 8.31 \\
\hline \multirow{3}{*}{$\begin{array}{l}\text { Medical } \\
\text { demand }\end{array}$} & \multirow{2}{*}{$\begin{array}{l}\text { Health condition: } \\
\text { (self assessment=0) }\end{array}$} & Basically healthy & 0.04 & 0.07 & 0.67 \\
\hline & & & 0.14 & 0.80 & 1.68 \\
\hline & $\begin{array}{l}\text { Chronic disease: } \\
\qquad(\text { no }=0)\end{array}$ & Have chronic disease & $-0.62^{*}$ & -0.30 & $-2.18^{* *}$ \\
\hline \multirow{5}{*}{$\begin{array}{l}\text { Medical } \\
\text { resource } \\
\text { availability }\end{array}$} & $\begin{array}{c}\text { The level of the } \\
\text { subjectively nearest } \\
\text { hospital from home } \\
\text { (level-2=0) }\end{array}$ & Level-3 & -0.57 & -17.93 & -3.21 \\
\hline & \multirow{4}{*}{$\begin{array}{l}\text { The subjective distance } \\
\text { to the nearest } \\
\text { level-3 hospital: } \\
(<1 \mathrm{~km}=0)\end{array}$} & $1-2 \mathrm{~km}$ & -0.42 & 16.43 & -3.21 \\
\hline & & $2-5 \mathrm{~km}$ & -0.09 & 17.77 & 0.04 \\
\hline & & $5-10 \mathrm{~km}$ & -1.19 & 16.31 & -16.40 \\
\hline & & $10 \mathrm{~km}$ and above & -0.68 & 17.02 & 1.30 \\
\hline
\end{tabular}




\begin{tabular}{|c|c|c|c|c|c|}
\hline & $\begin{array}{c}\text { The subjective distance } \\
\text { to the nearest } \\
\text { level- } 2 \text { hospital: } \\
(<1 \mathrm{~km}=0)\end{array}$ & $\begin{array}{c}1-2 \mathrm{~km} \\
2-5 \mathrm{~km} \\
5-10 \mathrm{~km} \\
10 \mathrm{~km} \text { and above }\end{array}$ & $\begin{array}{l}-0.07 \\
-1.16 \\
-1.31 \\
-1.51^{*}\end{array}$ & $\begin{array}{c}-17.50 \\
0.18 \\
3.79^{*} \\
0.75\end{array}$ & $\begin{array}{l}-4.51^{* *} \\
--6.00^{* *} \\
3.61 \\
-2.81\end{array}$ \\
\hline & $\begin{array}{c}\text { The level of the } \\
\text { objectively nearest } \\
\text { hospital from home: } \\
\text { (level-2=0) }\end{array}$ & Level-3 & 0.31 & 0.09 & --15.98 \\
\hline & $\begin{array}{c}\text { The objective distance } \\
\text { to the nearest } \\
\text { level-3 hospital: } \\
(<1 \mathrm{~km}=0)\end{array}$ & $\begin{array}{c}1-2 \mathrm{~km} \\
2-5 \mathrm{~km} \\
5 \mathrm{~km} \text { and above }\end{array}$ & $\begin{array}{l}-0.29 \\
-0.58 \\
-18.54\end{array}$ & $\begin{array}{r}-1.18 \\
-1.82 \\
-19.91\end{array}$ & $\begin{array}{l}16.89 \\
17.19 \\
14.42\end{array}$ \\
\hline & $\begin{array}{c}\text { The objective distance } \\
\text { to the nearest } \\
\text { level-2 hospital: } \\
(<1 \mathrm{~km}=0)\end{array}$ & $\begin{array}{c}1-2 \mathrm{~km} \\
2-5 \mathrm{~km} \\
5 \mathrm{~km} \text { and above }\end{array}$ & $\begin{array}{c}-0.16 \\
0.68 \\
-1.81^{* *}\end{array}$ & $\begin{array}{c}-1.89^{* * *} \\
-3.05^{*} \\
-2.41\end{array}$ & $\begin{array}{c}0.11 \\
0.25 \\
-15.28\end{array}$ \\
\hline Medical & $\begin{array}{l}\text { Understand medical } \\
\text { insurance } \\
\text { reimbursement policy: } \\
\text { (no understanding=0) }\end{array}$ & Understand & -0.14 & $-1.36^{* *}$ & -1.83 \\
\hline expenditure & $\begin{array}{c}\text { Prefer medical } \\
\text { institutions with higher } \\
\text { reimbursement rate: } \\
\left(Y_{e s}=0\right)\end{array}$ & $\begin{array}{c}\text { No } \\
\text { Not sure }\end{array}$ & $\begin{array}{l}-0.04 \\
-0.15\end{array}$ & $\begin{array}{l}0.39 \\
0.86\end{array}$ & $\begin{array}{l}-0.36 \\
2.06^{*}\end{array}$ \\
\hline \multicolumn{3}{|c|}{ Likelihood equation value } & \multicolumn{3}{|c|}{-316.48} \\
\hline
\end{tabular}

Note: ${ }^{*}, * * * *$ respectively represent significance at $10 \%, 5 \%$ and $1 \%$.

\section{The influencing factors of medical institution choices in the condition of general disease}

Model 2 shows the influencing factors of the elderly population's choices of different levels of medical institutions in the condition of general disease. Generally, general hospital (level-3) are the institutions with relatively concentrated and high-quality medical resources in Chinese megacities, and level-2 hospital and community health service centre have relatively lower quality medical services. The results show that age, marriage status, cohabitation status, health status, objective distance to hospital and attitudes toward medical expenditure are significant influencing factors.

As Table 3 displays, compared with low-age and high-age elderly people, middle-age elders with general disease have a high possibility to go to a level-2 hospital (district or regional hospital). Compared with elders who are married and are with their spouse, single and divorced elders have higher possibility to go to a level-3 hospital rather than a level-2 hospital or specialised hospital. Single elders are more concerned about whether they can get quality and standard care to better recover. Compared with elderly people who live with their spouse, those living with children have a higher possibility to go to level-2 hospital. A reasonable explanation is that those who live only 
with children may be younger. Also, compared with a self-assessed very healthy elderly population, self-assessed healthy, basically healthy and relatively unhealthy elderly people have a higher possibility to go to a level-2 hospital, and self-assessed very unhealthy elders have higher possibility to go to a level-3 hospital.

From a macro perspective, medical institution distance accessibility and holding medical insurance has significant impacts. The influence of the elders' subjectively perceived distance from home to hospital is not significant, while the objective distance is significant. In terms of objective distance, the elders whose homes are closest to a hospital is level-3 hospital have a higher possibility of going to the level-3 hospital. The further they live from a level-3 hospital, the higher possibility they have to go to a level-2 or health service center. The further they live from a level-2 hospital, the higher possibility they have to go to a level-2 hospital. This is not a contradictory conclusion because those communities close to level-2 hospital are mostly in the suburbs so there are less options to choose from. According to the current hierarchical diagnosis and treatment system and medical insurance reimbursement system in Shanghai, the higher level a hospital is, the lower medical insurance reimbursement rate it has. As Model 2 shows, compared with those who claim that they would go to hospital with a higher reimbursement rate, those who do not care or are unclear about reimbursement rate have a higher possibility to go to a level-3 hospital.

In addition, although there are influencing factors failed the significance test, the model coefficients still confirm the above characteristics about the difference between social group's medical treatment behavior choices. Elderly females are more likely to go to a level-2 hospital than elderly males in the condition of general disease. Compared with non-Shanghai hukou elders, elders with Shanghai hukou prefer to go to a level-3 hospital. This is due to the restrictions of long-distance medical insurance reimbursement on non-Shanghai hukou people. Usually, the settlement of medical insurance in different places is first promoted from level-3 hospital; this kind of segmentation of reimbursement system will be improved with the popularisation of national medical insurance settlement in different places. Elderly people who live in urban areas prefer to go 
to a level-3 hospital, partly due to rural residents' poor accessibility to hospital. Compared with the lowest income group, other relatively higher income groups have a higher possibility to go to a level-3 hospital, and as income levels increase, so does the preference to go to a level-3 hospital.

Table 3. Parameter estimation for medical institution choices of elderly population with general disease (control group = level-3 hospital).

\begin{tabular}{|c|c|c|c|c|}
\hline \multirow[b]{2}{*}{ sample } & \multirow[b]{2}{*}{ baseline group } & \multirow[b]{2}{*}{ comparable group } & \multicolumn{2}{|c|}{ Parameter estimation (2) } \\
\hline & & & $\begin{array}{c}\text { District or } \\
\text { regional hospital } \\
\text { (level-2) }\end{array}$ & $\begin{array}{l}\text { Others pecialised } \\
\text { hospitals or } \\
\text { community health } \\
\text { service centres) }\end{array}$ \\
\hline \multirow{7}{*}{$\begin{array}{l}\text { Demographic } \\
\text { and economic } \\
\text { characteristics }\end{array}$} & Gender:(Male=0) & Female & 0.55 & 0.31 \\
\hline & $\begin{array}{c}\text { Age: } \\
(60-64 \text { years old }=0)\end{array}$ & $\begin{array}{c}\text { 65-69 Years old } \\
70-74 \text { Years old } \\
75-79 \text { Years old } \\
80 \text { Years old and } \\
\text { above }\end{array}$ & $\begin{array}{l}-0.44 \\
0.52 \\
1.04^{*} \\
-0.27\end{array}$ & $\begin{array}{l}-0.62 \\
0.68 \\
0.36 \\
0.35\end{array}$ \\
\hline & $\begin{array}{l}\text { Income (retirement } \\
\text { pension): } \\
(<1000 \text { Yuan }=0)\end{array}$ & $\begin{array}{c}\text { 1000-1999 Yuan } \\
\text { 2000-2999 Yuan } \\
\text { 3000-3999 Yuan } \\
\text { 4000-4999 Yuan } \\
\text { 5000-5999 Yuan } \\
6000 \text { Yuan and } \\
\text { above }\end{array}$ & $\begin{array}{l}-0.63 \\
-1.33 \\
-0.34 \\
-0.75 \\
-1.14 \\
-0.94\end{array}$ & $\begin{array}{l}-0.77 \\
-1.68 \\
-0.28 \\
-0.92 \\
-1.32 \\
-1.18\end{array}$ \\
\hline & $\begin{array}{l}\text { Marriage status: } \\
\text { (Married with } \\
\text { spouse }=0)\end{array}$ & $\begin{array}{l}\text { Unmarried } \\
\text { Divorce } \\
\text { Widow }\end{array}$ & $\begin{array}{l}-0.40 \\
-1.70^{* *} \\
-0.87\end{array}$ & $\begin{array}{l}0.13 \\
-2.24^{* *} \\
-0.52\end{array}$ \\
\hline & $\begin{array}{l}\text { cohabitation status: } \\
\text { (husband and wife=0) }\end{array}$ & $\begin{array}{l}\text { Elderly people } \\
\text { living alone } \\
\text { With elder (same } \\
\text { generation) } \\
\text { With children } \\
\text { With three } \\
\text { generations }\end{array}$ & $\begin{array}{l}0.78 \\
0.20 \\
0.83^{* *} \\
0.95^{*}\end{array}$ & $\begin{array}{l}0.81 \\
-1.20 \\
0.25 \\
0.76\end{array}$ \\
\hline & $\begin{array}{c}\text { Education level: } \\
\text { (Primary school and } \\
\text { below }=0)\end{array}$ & $\begin{array}{l}\text { Middle school } \\
\text { High school or } \\
\text { technical secondary } \\
\text { school } \\
\text { Junior college }\end{array}$ & $\begin{array}{l}-0.14 \\
-0.35 \\
0.07\end{array}$ & $\begin{array}{l}0.44 \\
-0.14 \\
0.25\end{array}$ \\
\hline & $\begin{array}{c}\text { Hukou: } \\
\text { (Rural=0) } \\
\text { Hukou: } \\
\text { (non-Shanghai } h u k o u=0 \text { ) }\end{array}$ & $\begin{array}{c}\text { Urban } \\
\text { Shanghai hukou }\end{array}$ & $\begin{array}{l}-1.11 \\
-0.54\end{array}$ & $\begin{array}{l}-0.52 \\
-0.66\end{array}$ \\
\hline \multirow{2}{*}{$\begin{array}{l}\text { Medical } \\
\text { demand }\end{array}$} & $\begin{array}{l}\text { Health condition: (self- } \\
\text { ssessment }=0 \text { ): }\end{array}$ & $\begin{array}{l}\text { Basically healthy } \\
\text { Unhealthy }\end{array}$ & $\begin{array}{c}0.75^{* *} \\
0.26\end{array}$ & $\begin{array}{l}0.58^{*} \\
0.48\end{array}$ \\
\hline & $\begin{array}{l}\text { Chronic disease: } \\
\qquad(\text { no }=0)\end{array}$ & $\begin{array}{l}\text { having chronic } \\
\text { disease }\end{array}$ & -0.05 & -0.33 \\
\hline $\begin{array}{l}\text { Medical } \\
\text { resource } \\
\text { availability }\end{array}$ & $\begin{array}{l}\text { The level of the } \\
\text { subjectively nearest } \\
\text { hospital from home: }\end{array}$ & Level-3 & -15.95 & -14.83 \\
\hline
\end{tabular}




\begin{tabular}{|c|c|c|c|c|}
\hline & (level-2=0) & & & \\
\hline & $\begin{array}{l}\text { The subjective distance } \\
\text { to the nearest } \\
\text { level-3 hospital: } \\
(<1 \mathrm{~km}=0)\end{array}$ & $\begin{array}{c}1-2 \mathrm{~km} \\
2-5 \mathrm{~km} \\
5-10 \mathrm{~km} \\
10 \mathrm{~km} \text { and above }\end{array}$ & $\begin{array}{r}0.35 \\
0.38 \\
-0.09 \\
0.24\end{array}$ & $\begin{array}{r}-0.82 \\
0.01 \\
-1.05 \\
-0.36\end{array}$ \\
\hline & $\begin{array}{l}\text { The subjective distance } \\
\text { to the nearest } \\
\text { level- } 2 \text { hospital: } \\
(<1 \mathrm{~km}=0)\end{array}$ & $\begin{array}{c}1-2 \mathrm{~km} \\
2-5 \mathrm{~km} \\
5-10 \mathrm{~km} \\
10 \mathrm{~km} \text { and above }\end{array}$ & $\begin{array}{l}-14.95 \\
-15.36 \\
-14.79 \\
-16.00\end{array}$ & $\begin{array}{r}-14.83 \\
-15.13 \\
-14.06 \\
-15.35\end{array}$ \\
\hline & $\begin{array}{c}\text { The level of the } \\
\text { objectively nearest } \\
\text { hospital from home: } \\
\text { (level-2=0) }\end{array}$ & Level-3 & $-1.15^{* *}$ & $-1.65^{* *}$ \\
\hline & $\begin{array}{l}\text { The objective distance } \\
\text { to the nearest } \\
\text { level-3 hospital: } \\
(<1 \mathrm{~km}=0)\end{array}$ & $\begin{array}{c}1-2 \mathrm{~km} \\
2-5 \mathrm{~km} \\
5 \mathrm{~km} \text { and above }\end{array}$ & $\begin{array}{l}1.17^{*} \\
1.81 \\
2.38\end{array}$ & $\begin{array}{l}1.64^{* *} \\
3.80^{* * *} \\
-13.52\end{array}$ \\
\hline & $\begin{array}{l}\text { The objective distance } \\
\text { to the nearest } \\
\text { level- } 2 \text { hospital: } \\
(<1 \mathrm{~km}=0)\end{array}$ & $\begin{array}{c}1-2 \mathrm{~km} \\
2-5 \mathrm{~km} \\
5 \mathrm{~km} \text { and above }\end{array}$ & $\begin{array}{l}0.96^{*} \\
0.16 \\
1.50\end{array}$ & $\begin{array}{l}0.83 \\
1.21^{*} \\
1.88^{*}\end{array}$ \\
\hline Medical & $\begin{array}{l}\text { Understand medical } \\
\text { insurance } \\
\text { reimbursement policy: } \\
\text { (no understanding=0) }\end{array}$ & Understand & 0.10 & 0.18 \\
\hline expenditure & $\begin{array}{c}\text { Prefer medical } \\
\text { institutions with higher } \\
\text { reimbursement rate: } \\
(\text { Yes }=0)\end{array}$ & $\begin{array}{c}\text { No } \\
\text { Not sure }\end{array}$ & $\begin{array}{l}-0.28 \\
-0.28\end{array}$ & $\begin{array}{l}-0.79^{* *} \\
-0.48\end{array}$ \\
\hline \multicolumn{3}{|c|}{ Likelihood equation value } & \multicolumn{2}{|c|}{-399.47} \\
\hline
\end{tabular}

Note: ${ }^{*},{ }^{* *},{ }^{* *}$ respectively represent significance at $10 \%, 5 \%$ and $1 \%$.

The influencing factors of medical institution choices in the condition of severe disease

As Table 4 shows, compared with low-age elders, middle and high-age elders have higher possibility to go to a level-2 hospital. This may be because the older elders prefer conservative medical treatment so the possibility to go to a level-3 hospital is lower. Compared with the lowest income elders, relatively higher income groups have a higher possibility to go to a level-3 hospital rather than a level-2 hospital. The coefficients in Table 3 are all negative. Compared with the elderly population who live with their spouse, those living with three generations have a higher possibility to go to a level-3 hospital than a level-2 hospital because their medical treatment behavior is positively influenced by their children, such as financial and spiritual supports. In the condition of severe disease, compared with those living in rural areas, those living in urban areas have a higher possibility to go to a level-3 hospital than a level-2 hospital, because level-3 hospital's accessibility 
in urban areas is better. Also, compared with self-assessed very healthy elders, elders with other self-assessed health conditions (relatively healthy, basically healthy, relatively unhealthy and very unhealthy) have a preference to go to a level-3 hospital rather than a level-2 hospital.

From a macro perspective, the distance of residential location to hospital significantly influences elderly people's medical treatment behavior. In the condition of severe disease, the subjective distance to hospital has significant influences while the objective distance does not. Compared with elders who perceive the distance to the nearest level-3 hospital as minimal, other elders are more likely to go to a level-3 hospital. Compared with elders who perceive the distance to the nearest level-2 hospital as minimal, other elders are also more likely to go to a level-3 hospital. The analysis of hospital distance accessibility shows that in the condition of severe disease, the preference is to visitalevel-3 hospital despite distance.

Also, from the perspective of non-significant influencing factors, compared with elderly male, elderly females are more likely to go to a level-2 hospital in the condition of severe disease. Compared with non-Shanghai hukou elders, Shanghai hukou elders are more likely to go to a level-3 hospital. Those elders who understand medical insurance policy have higher possibility to go to alevel-2 hospital with a higher reimbursement rate.

Table 4. Parameter estimation for medical institution choices of elderly population with severe disease (control group = level-3 hospital).

\begin{tabular}{|c|c|c|c|c|}
\hline \multirow[b]{2}{*}{ sample } & \multirow[b]{2}{*}{ baseline group } & \multirow[b]{2}{*}{ comparable group } & \multicolumn{2}{|c|}{ Parameter estimation (3) } \\
\hline & & & $\begin{array}{c}\text { District or } \\
\text { regional } \\
\text { hospital } \\
\text { (level-2) }\end{array}$ & $\begin{array}{l}\text { Others specialized } \\
\text { hospitals or } \\
\text { community health } \\
\text { service centres) }\end{array}$ \\
\hline \multirow{10}{*}{$\begin{array}{l}\text { Demographic } \\
\text { and economic } \\
\text { characteristics }\end{array}$} & Gender:(Male=0) & Female & 0.46 & -0.03 \\
\hline & \multirow{4}{*}{$\begin{array}{c}\text { Age: } \\
(60-64 \text { years old=0) }\end{array}$} & 65-69 Years old & -0.32 & -0.60 \\
\hline & & 70-74 Years old & 0.27 & -0.08 \\
\hline & & 75-79 Years old & $1.08^{*}$ & -0.39 \\
\hline & & $\begin{array}{c}80 \text { Years old and } \\
\text { above }\end{array}$ & 0.76 & -1.34 \\
\hline & \multirow{5}{*}{$\begin{array}{c}\text { Income (retirement } \\
\text { pension): } \\
(<1000 \text { Yuan=0) }\end{array}$} & 1000-1999 Yuan & $-1.58^{*}$ & 14.06 \\
\hline & & 2000-2999 Yuan & $-2.02^{*}$ & 14.74 \\
\hline & & 3000-3999 Yuan & -0.84 & 14.45 \\
\hline & & 4000-4999 Yuan & -1.35 & 13.84 \\
\hline & & 5000-5999 Yuan & $-2.71^{* *}$ & 13.43 \\
\hline
\end{tabular}




\begin{tabular}{|c|c|c|c|c|}
\hline & & $\begin{array}{l}6000 \text { Yuan and } \\
\text { above }\end{array}$ & -1.01 & 11.69 \\
\hline & \multirow{3}{*}{$\begin{array}{l}\text { Marriage status: } \\
\text { (Married with } \\
\text { spouse }=0 \text { ) }\end{array}$} & Unmarried & -0.44 & 0.07 \\
\hline & & Divorce & 1.17 & -0.81 \\
\hline & & Widow & -0.60 & -0.13 \\
\hline & \multirow{4}{*}{$\begin{array}{l}\text { cohabitation status: } \\
\text { (husband and wife }=0 \text { ) }\end{array}$} & $\begin{array}{l}\text { Elderly people } \\
\text { living alone }\end{array}$ & -0.99 & 0.36 \\
\hline & & $\begin{array}{l}\text { With elder (same } \\
\text { generation) }\end{array}$ & 0.24 & 0.70 \\
\hline & & With children & 0.37 & 0.26 \\
\hline & & $\begin{array}{l}\text { With three } \\
\text { generations }\end{array}$ & $-1.21^{*}$ & 0.19 \\
\hline & \multirow{3}{*}{$\begin{array}{c}\text { Education level: } \\
\text { (Primary school and } \\
\text { below }=0 \text { ) }\end{array}$} & Middle school & -0.26 & -0.01 \\
\hline & & $\begin{array}{l}\text { High school or } \\
\text { technical } \\
\text { secondary school }\end{array}$ & -0.11 & -0.22 \\
\hline & & Junior college & 0.13 & 0.78 \\
\hline & $\begin{array}{l}\text { Hukou: } \\
\text { (Rural=0) }\end{array}$ & Urban & $-1.79^{* *}$ & 1.82 \\
\hline & $\begin{array}{c}\text { Hukou: } \\
\text { (non-Shanghai } \\
\text { hukou=0) }\end{array}$ & Shanghai hukou & -0.77 & 14.79 \\
\hline \multirow{3}{*}{$\begin{array}{l}\text { Medical } \\
\text { demand }\end{array}$} & Health condition (self- & Basically healthy & 0.22 & -0.04 \\
\hline & ssessment=0): & Unhealthy & -0.01 & $-2.38^{* *}$ \\
\hline & Chronic disease: (no=0) & $\begin{array}{l}\text { having chronic } \\
\text { disease }\end{array}$ & 0.27 & -0.40 \\
\hline \multirow{16}{*}{$\begin{array}{l}\text { Medical } \\
\text { resource } \\
\text { availability }\end{array}$} & $\begin{array}{c}\text { The level of the } \\
\text { subjectively nearest } \\
\text { hospital from home: } \\
\text { (level-2=0) }\end{array}$ & Level-3 & 0.83 & 1.44 \\
\hline & \multirow{4}{*}{$\begin{array}{c}\text { The subjective distance } \\
\text { to the nearest } \\
\text { level-3 hospital } \\
(<1 \mathrm{~km}=0)\end{array}$} & $1-2 \mathrm{~km}$ & $-2.91^{* *}$ & -1.15 \\
\hline & & $2-5 \mathrm{~km}$ & $-2.61^{* *}$ & -1.01 \\
\hline & & $5-10 \mathrm{~km}$ & -2.03 & -1.42 \\
\hline & & $10 \mathrm{~km}$ and above & -1.84 & $-2.70^{*}$ \\
\hline & \multirow{4}{*}{$\begin{array}{c}\text { The subjective distance } \\
\text { to the nearest } \\
\text { level-2 hospital: } \\
(<1 \mathrm{~km}=0)\end{array}$} & $1-2 \mathrm{~km}$ & $-1.43^{* *}$ & 1.17 \\
\hline & & $2-5 \mathrm{~km}$ & $-2.15^{* * *}$ & 0.41 \\
\hline & & $5-10 \mathrm{~km}$ & 1.62 & -17.67 \\
\hline & & $10 \mathrm{~km}$ and above & $-1.75^{*}$ & 0.48 \\
\hline & $\begin{array}{c}\text { The level of the } \\
\text { objectively nearest } \\
\text { hospital from home } \\
\text { (level-2=0) }\end{array}$ & Level-3 & -16.30 & 0.19 \\
\hline & \multirow{3}{*}{$\begin{array}{c}\text { The objective distance } \\
\text { to the nearest } \\
\text { level-3 hospital: } \\
(<1 \mathrm{~km}=0)\end{array}$} & $1-2 \mathrm{~km}$ & 15.35 & -0.47 \\
\hline & & $2-5 \mathrm{~km}$ & 15.30 & -13.59 \\
\hline & & $5 \mathrm{~km}$ and above & 37.30 & 14.76 \\
\hline & \multirow{3}{*}{$\begin{array}{c}\text { The objective distance } \\
\text { to the nearest } \\
\text { level- } 2 \text { hospital: } \\
(<1 \mathrm{~km}=0) \\
\end{array}$} & $1-2 \mathrm{~km}$ & -0.21 & 0.46 \\
\hline & & $2-5 \mathrm{~km}$ & -0.86 & $1.52^{* *}$ \\
\hline & & $5 \mathrm{~km}$ and above & -0.28 & 1.21 \\
\hline
\end{tabular}




\begin{tabular}{|c|c|c|c|c|}
\hline \multirow{2}{*}{$\begin{array}{c}\text { Medical } \\
\text { expenditure }\end{array}$} & $\begin{array}{c}\text { Understand } \\
\text { medical insurance } \\
\text { reimbursement policy } \\
\text { (no understanding=0) }\end{array}$ & Understand & 0.52 & 0.58 \\
\hline & $\begin{array}{c}\text { Prefer medical } \\
\text { institutions } \\
\text { with higher } \\
\text { reimbursement rate } \\
\text { (Yes=0) }\end{array}$ & Not sure & 0.26 & $\begin{array}{c}-0.16 \\
0.32\end{array}$ \\
\hline \multicolumn{3}{|c|}{ Likelihood equation value } & \multicolumn{2}{|c|}{-278.24} \\
\hline
\end{tabular}

Note: ${ }^{*}, * * * *$ respectively represent significance at $10 \%, 5 \%$ and $1 \%$.

\section{Conclusion and Discussion}

Factors such as individual socioeconomic characteristics and macro medical resource allocation and medical insurance policy have significant impact on the elderly population's medical treatment behavior across the three medical conditions. These factors include age, health condition, marriage status, cohabitation status, distance accessibility to hospital and medical expenditure understanding and attitudes. This indicates that the elderly's medical treatment behavior based on rational choices around price, demand and supply of medical services. In the context of an aging population, more families will face heavier support obligations and the medical needs of the elderly population is increasing. Medical supply should be reformed according to elderly population demand characteristics with any 'one-size-fits-all' strategies to be avoided.

This study demonstrates how Chinese elderly people rely heavily on family support. For example, for severe disease, elderly population who live with three generations are more likely to choose high-quality medical resources. By investing more energy and money on elders, family members improve elders' health and also the intergenerational family relationship. Meanwhile, elderly people with higher retirement pension will also fund their families' daily living expenses. Income has significant impact on elderly population's medical preferences for severe disease, but not when faced with physical discomfort or general disease. This is partly because the income level and medical security of the elderly population in Shanghai are high. There is no significant difference in medical expenditure for general disease. Medical expenditure variables such as graded medical insurance reimbursement policy and the elderly person's attitudes toward the reimbursement policy also have no significant impacts on their choice of medical institution. This is 
possibly because the overall level of elderly people's medical security in Shanghai is relatively great.

The finding of this study is in line with previous conclusions, in which medical treatment behaviour has a distance friction effect: the closer to hospital, the stronger the tendency to choose, and this is especially the case for level-3 hospitals. In most cases, elderly people without Shanghai hukou and who do not have medical insurance display less preference to choose a level-3 hospital and instead prefer the pharmacy or staying at home so they can save on medical costs. The finding also shows that the various factors have no significant influence on choosing a community health service centre. This reflects the lower effectiveness of community health service centres compared to a level-3 or level-2 hospital. The hierarchical medical institution strucutre can only be promoted effectively when elderly patients have stronger health awareness and actively choose community health service centres.

At present, Shanghai and other big Chinese cities are in the stage of population suburbanization, but the allocation of public service resources, such as medical, health and education, still presents a strong centripetal agglomeration in space. Analyzed the balance and change of medical resources allocation in different levels of Shanghai since the new medical reform, and found that the allocation of medical resources in Shanghai is still "strong in central city and weak in suburbs" [40]. The balance of medical resources allocation at community level is higher than that at hospital level, but the pattern of resource allocation in traditional central district has not changed obviously. The contradiction between centralization of medical and health resources and suburbanization in large cities such as Shanghai has affected the equality of public resource space allocation. In addition, the allocation of medical and health resources such as Shanghai is "average" but not "equal". In actual operation in major cities in China, public service resources are often evenly distributed according to administrative divisions. Street towns with a resident population of up to 300,000 have the same number of service personnel as those with a resident population of only 30,000; The establishment of public service institutions has not fully considered the spatial 
fairness and accessibility. In terms of the number of service institutions, there is no difference between the administrative area with a larger area and the administrative area with a smaller area at the same level. Equitable accessibility between individuals. The central urban area of Shanghai has constructed various levels of rich medical resources such as city-level hospitals, district-level hospitals and district hospitals, and community health service points. The medical resources available to residents are rich and convenient. However, in the suburbs of Shanghai, especially in the far suburbs, there is a lack of high-level medical resources, and even basic hospitals and community health service points are scarce.

There is a "increasing" phenomenon in the allocation of medical resources to high-level medical care. As the most important secondary hospitals and community health service centers at the grassroots level, they can not meet the needs of the sick people effectively. There are "lack of people" (lack of experts in secondary hospitals, lack of general practitioners in community health service centers), "lack of money" (unbalance of the two lines of income and expenditure caused by the difference in financial situation of each district) and "lack of equipment". Many street community health service centers in Shanghai are in short supply of medical personnel, and provide limited health care services, which can only guarantee normal outpatient operations, and the medical quality of the inspection and residential service points, as well as the medical services needed by the elderly, such as health publicity and preventive education, are not satisfactory. As the institution most likely to provide medical services to the elderly in a flexible manner, there is a shortage of medical funds and a shortage of medical resources (hardware equipment and human resources) to community health service center. The policy arrangement has carried out special tasks such as disease prevention and control, health file tracking and diagnosis for the elderly, However, the imbalance of power and financial power not only seriously affected the effectiveness of institutional arrangements, but also can't be provided targeted medical treatment services to the elderly. 
The pattern of inefficient allocation of medical resources is not only related to the current Chinese medical system, but also affected by market factors (medical market failure, moral hazard is difficult to restrain, etc.), regional differences (such as regional economic conditions and regional planning, geographical location differences), institutional environment and legal practices. China's medical services are moving from plan to market, because of the imperfect design of the mechanism and the low effectiveness of the rule of law supervision, the supply of medical factors resources in the medical market is unreasonable, the allocation of medical products is inefficient, medicine is not divided, the moral hazard caused by asymmetric information, and so on. In addition, the difference of medical demand-side structure determines the difference of purchasing ability, and the contradiction of effective demand structure caused by this income constraint is not alleviated by the improvement of market efficiency. Therefore, while strengthening the reform of medical marketization and improving the efficiency of supply of scarce medical products, the Chinese government should also strengthen the reform of system design and strengthen the total supply and structural balance of geriatric care, especially the weak geriatric products.

There are three limitations in this study. First, the gender ratio was not coordinated and more females responses were received. This is because the places selected to issue questionnaires were in squares and parks, where females are more active than males. Second, in the samples received, there were less rural elderly people. This is because those holding rural hukou are less than those holding urban hukou in Shanghai. Third, the results of this study were based on elderly people's medical behaviour in Shanghai, which may not be representative of cities in other parts of China, especially central and western provinces.

In the context of an aging society in China, the need for medical reform faces significant issues such as justice between different groups of people, uneven distribution of medical resources in urban and rural areas and long-distance medical insurance in the current hukou system. We therefore suggest to strengthen government policies for the low-income elderly population, guarantee their medical needs and promote the rational distribution of medical resources. This 
requires deeper research on the influencing factors behind the elderly population's medical treatment choices. This study plays a leading role for future relevant research on this topic

\begin{abstract}
Abbreviations
CHN: China; CHNS: China Health and Nutrition Survey; GIS: Geographic Information System; OLS: Ordinary Least Square; NBM: Negative Binominal Model; FMNB: Finite Mixed Negative Binominal; MLM: Multiple Logit Model; CLM: Conditional Logit Model; CLHLS: Chinese Longitudinal Healthy Longevity Survey; IIA: Independence of Irrelevant Alternatives; MLE: Maximum Likelihood Estimation;
\end{abstract}

\title{
Ethics approval and consent to participate
}

The original survey obtained ethical approval from the Institute of Economic Development of East China University of Technology Scientific. The questionnaire used in our study was developed for this study. In addition, written consent was obtained from each elderly visited or their relatives which can help them fill out questionnaires. Permission to access/use the data analyzed in this study was provided by the Institute of Economic Development of East China University of Technology Scientific.

\section{Consent for publication}

Not Applicable.

\section{Availability of data and material}

The datasets used and/or analysed during the current study are available from the corresponding author on reasonable request.

\section{Competing interests}

The authors declare they have no competing interests.

\section{Funding}

National Natural Science Foundation of China, Grant/Award Number: 71874054; Shanghai

Education Committee Humanities and Social Sciences Major Project, Grant/Award Number: 2017 01 - 07 - 00 - 02 - E00008; Shanghai Soft Science Foundation Project, Grant/Award Number: 19692109100;

\section{Authors' contributions}

ShangguangYang, Danyang Wang, Chunlan Wang, Chen Li, and Mark Wang conceptualized the design of the study. Danyang Wang and Chen Li participated in data extraction, and analysis; ShangguangYang, Chunlan Wang and Mark Wang provided review of the methodology and analysis results; All authors contributed to the writing of this paper and all have read and approved the final manuscript.

\section{Acknowledgements}

We would like to acknowledge professor Shangguang Yang and professor Chunlan Wang' students participated in the survey. We grateful to the Hong Kong Baptist University's Kevin lo and East China University of Technology's Xiaotong Ye for their valuable comments in the revision of the paper. 
References:

1. The Present Situation of Population Aging in Shanghai

[http://tji.sh.gov.cn/tifx/20181123/0014-1002033.html]

2. Arrow $\mathrm{KJ}$ : Uncertainty and the welfare economics of medical care. In:

Uncertainty in economics, edn.: Elsevier; 1978: 345-375.

3. Becker GS, Chiswick BR: Education and the Distribution of Earnings. The American Economic Review 1966, 56(1/2):358-369.

4. Grossman M: On the concept of health capital and the demand for health. Journal of Political economy 1972, 80(2):223-255.

5. Deb $\mathrm{P}$, Trivedi PK: The structure of demand for health care: latent class versus two-part models. Journal of health economics 2002, 21(4):601-625.

6. Wagstaff A: The demand for health: some new empirical evidence. Journal of health economics 1986, 5(3):195-233.

7. Zhou X: The Canada Healthy City Program:Practice and Experience. Journal of Public Management 2006(3):68-73.

8. Yu M, He S, Wu D, Zhu H, Webster C: Examining the Multi-Scalar Unevenness of High-Quality Healthcare Resources Distribution in China. International journal of environmental research and public health 2019, 16(16):2813.

9. Daniels $\mathrm{N}$ : Just health:meeting health needs fairly: Cambridge University Press; 2007.

10. Zhu X: Study on Effective Supply of Public Medical Service Introduction and Governance of Private Capital. China Administration 2010, 5:58-60.

11. Zheng X, Xu J: A Study on Contemporary Medical Justice from the Perspective of the Comparison of Chinese and Western Concept of Justice. Theory of Value and Ethical Studies 2016(01):220-230.

12. Song X: The Management of Medical Order Emphasis on Medical. JusticeManagement World 2014(02):172-173.

13. Sun Y, Wang P: Ethical Consideration of Medical Security for Patients with Rare Diseases. Chinese Medical Ethics 2019, 32(09):1143-1146.

14. Xie E: Income-related Inequality of Health and Health Care Utilization. Economic Research Journal 2009, 44(02):92-105.

15. Ma S, Zang W, Gan L: The Effect of the New Rural Cooperative Medical System on Rural Household Food Consumption. China Economic Quarterly 2011, 10(01):249-270.

16. Zhou G, Fan G, Shen G: The Income Disparity, the Social Capital and Health: A Case Study Based on China Family Panel Studies. Management World 2014(07):12-21+51.

17. Ma C, Gu H, Sun X: The Effects of Urban-Rural Integrated Medical Insurance System on Substantial Equity of Health Care and HeathBased on Equality of Opportunity. Journal of Public Management 2017, 14(02): 97-109+157.

18. Talen $E$, Anselin L: Assessing spatial equity: an evaluation of measures of accessibility to public playgrounds. Environment and planning $A 1998$, 30(4):595-613.

19. Liang B, Qian S, Zhang W: A Study on the Spatial Distribution and Rationality of Medical Conditions in All Provinces of China. Chinese Journal of Health Statistics 2017, 34(03):455-458.

20. Gu K, Liu S, Sun H, Zhou Y: Accessibility and Equity of Urban Medical Resources Based on Geographic Information System. Investigación Clínica 2019, 60(4). 
21. Lu C, Zhang Z, Lan X: Impact of China's referral reform on the equity and spatial accessibility of healthcare resources: A case study of Beijing. Social Science \& Medicine 2019, 235:112386.

22. Shi B, Wu S: Spatial Analysis of Access to Care:Geographic Distribution of China's Top Hospitals from The Perspective of Embedded Stratification Theory. Journal of Gansu Administration Institute 2019(05):94-103+128.

23. Deb $P$, Trivedi PK: Demand for medical care by the elderly: a finite mixture approach. Journal of applied Econometrics 1997, 12(3):313-336.

24. Solé-Auró A, Guillén M, Crimmins EM: Health care usage among immigrants and native-born elderly populations in eleven European countries: results from SHARE. The European Journal of Health Economics 2012, 13(6):741-754.

25. Chen Y, Xu S: Health Status, Welfare Demand and Prospects of Elderly Population in China. Population Journal 2011(02):34-39.

26. Dou Y: Review of research on overseas medical treatment behaviour. Rural Economy and Science Technology 2017(28):222-223.

27. Xing $\mathrm{H}$, Shen $\mathrm{Y}$, Zhao H, Yu M: The Corresponding Analysis of Rural Residents' medical treatment behaviours and its influencing factors. Chinese Rural Health Service Administration 2002(22):12-15

28. Zhao Z, Hou Z: Health Demand in Urban China and Grossman Model: Evidence from Cross-sectional Analysis. Economic Research Journal 2005(10):79-90.

29. Long T, Li X, Yang G, Zeng L, Wei C, Chen J: A Study on the Medical Treatment Behaviours of Tuberculosis Patients in Sichuan. Modern Preventive Medicine 2008, 35:1301-1304.

30. Bao Y, Tao M, Liu W: Analysis on Intention of Visiting Doctor and Affecting Factors in Community Residents of Shanghai. Chinese Journal of General Practice 2009, 7(06):551-554

31. Qiu Y, Zhai S: System Transformation and Development Path on Medical Care. Population \& Economics 2014(02):114-119.

32. Yang Q, Liu J: The Empirical Analysis of Medical Security and Elderly People Medical Service Demand. Shanghai Journal of Economics 2013, 25(10):64-74.

33. Gao H, Sun H, Wu Q, Hao Y, Li Y, He J, Zhu H, Li X: Analysis on the infl uencing factors of medical service utilization of the elderly population in Heilongjiang Province in2013. Chinese Health Resources 2016, 19:503-506.

34. Zheng L: Has Health Insurance System Changed Health Care Seeking Behavior?_Evidence from Chinese CHNS. Public Finance Research 2017(02):84-97.

35. Gertler P, Locay L, Sanderson W: Are user fees regressive?: The welfare implications of health care financing proposals in Peru. Journal of econometrics 1987, 36(1-2):67-88.

36. Gertler P, Gaag JVD: The willingness to pay for medical care: evidence from two developing countries: Johns Hopkins University Press; 1990.

37. Mwabu G, Ainsworth M, Nyamete A: Quality of medical care and choice of medical treatment in Kenya: an empirical analysis. Journal of Human Resources 1993:838-862.

38. Wang J, Chang Z, Liu H: Health Care Demand and Choice of Medical Treatment. Economic Research Journa/ 2008, 7.

39. Grilo LM, Grilo HL, Gonçalves SP, Junça A: Multinomial logistic regression in workers' health. In: AIP Conference Proceedings: 2017: AIP Publishing LLC; 2017: 110010. 
40. Zhang L, Li L: Study on the Equilibrium of Spatial Allocation of Medical Resources at Different Levels in Shanghai. Urban Development Studies 2019, 26(06):1-6. 


\section{Supplementary Files}

This is a list of supplementary files associated with this preprint. Click to download.

- Questionnaire.docx 